\title{
Revista Brasileira de Enfermagem REBEn \\ Experiência de pais e outros familiares no cuidado à criança e ao adolescente após o Transplante de Medula Óssea
}

Experience of parents and other family members in the care to children and adolescents after Bone Marrow Transplantation

Experiencia de padres y otros familiares en el cuidado al niño y al adolescente después del Transplante de Medula Ósea

\section{Jane Cristina Andres}

Enfermeira. Professora do Instituto Superior e Centro Educacional Luterano de Santa Catarina - Bom Jesus (IELUSC). jane andres@uol.com.br

\section{Regina Aparecida Garcia de Lima}

Enfermeira. Professora Associada do Departamento de Enfermagem da Escola de Enfermagem de Ribeirão Preto da Universidade de São Paulo. limare@eerp.usp.br

Semiramis Melani Melo Rocha

Enfermeira. Professora Titular do Departamento de Enfermagem da Escola de Enfermagem de Ribeirão Preto da Universidade de São Paulo. smmrocha@eerp.usp.br

Este trabalho é parte da dissertação de mestrado apresentada à Escola de Enfermagem de Ribeirão Preto da Universidade de São Paulo, inserido na linha de pesquisa "Assistência à Criança e ao Adolescente".

\section{RESUMO}

O objetivo deste trabalho é descrever como os pais e outros familiares de crianças e adolescentes submetidos ao Transplante de medula Ossea (TMO) vivenciam esta experiência, especialmente na fase pós operatória. Participaram do estudo treze responsáveis por onze pacientes menores de dezoito anos. Utilizamos como instrumento de coleta de dados a entrevista semi-estruturada com os responsáveis. Para a análise dos dados recorremos a abordagem qualitativa. Através das entrevistas identificamos os seguintes temas: impacto do transplante e cotidiano familiar. Os resultados indicam que pela complexidade do TMO é indispensável o conhecimento da realidade familiar do paciente pois esta tem papel fundamental na sua qualidade de vida. Assim identificar condições, vivências e modo de vida das famílias permite trabalhar com base em suas reais necessidades, respeitando suas possibilidades e limites.

Descritores: Enfermagem pediátrica; Transplante de medula óssea; Adolescente.

\section{ABSTRACT}

The purpose of this study is to describe how parents and other family members of children and adolescents submitted to Bone Marrow Transplantation, specially in the post operative period. Thirteen subjects responsible to the care of eleven patients under 18 years old participated in the study. Authors used semi-structured interviews to collected data. Data were analyzed through a qualitative approach. The following themes were identified: impact of transplantation and family life. Results indicated that due to the complexity of Bone Marrow Transplantation, the knowledge on the family reality is crucial as family plays a fundamental role in patients' quality of life. Therefore, to identify conditions, experiences and the life style of families enable the work based on their real needs, respecting their possibilities and limitations.

Descriptors: Pediatric nursing; Bone marrow transplantation; Adolescent.

\section{RESUMEN}

El objetivo de este trabajo es describir como los padres y otros familiares de niños y adolescentes sometidos al Transplante de Médula Ósea vivencian esa experiencia, especialmente después del transplante. Participaron del estudio trece responsables por once pacientes con menos de 18 años. Utilizamos como instrumento de recolección de datos la entrevista semi-estructurada con los responsables. Para el análisis de datos fue utilizado el abordaje cualitativo. A través de entrevistas fueron identificados los siguientes temas: impacto del transplante y cotidiano familiar. Los resultados indican que por la complejidad del Transplante de Médula Ósea es indispensable el conocimiento de la realidad familiar del paciente pues esta tiene un papel fundamental en su calidad de vida. Así, identificar condiciones, vivencias y el modo de vida de las familias permite trabajar con base en sus reales necesidades, respetando sus posibilidades y limites.

Descriptores: Enfermería pediátrica; Transplante de médula ósea; Adolescente.

Sanders JC, Lima RAG, Rocha SMM. Experiência de pais e outros familiares no cuidado à criança e ao adolescente após o Transplante de Medula Óssea. Rev Bras Enferm 2005 jul-ago; 58(4):416-21.

\section{INTRODUÇÃO}

No transcorrer dos anos, o transplante de medula óssea - TMO - tornou-se uma modalidade terapêutica utilizada de maneira crescente em algumas doenças na fase adulta e na infância; metade dos transplantes de medula óssea realizados no mundo ocorre em crianças e adolescentes ${ }^{(1)}$.

A agressividade deste procedimento terapêutico, decorrente dos efeitos colaterais da quimioterapia/radioterapia, acarreta comprometimento múltiplo de órgãos e tecidos e depressão imunológica. Estas complicações já estão amplamente documentadas na literatura médica nacional e internacional ${ }^{(1-4)}$.

Analisando a literatura de enfermagem sobre transplante de medula óssea, observa-se a 
presença de estudos descritivos que discutem questões relacionadas ao histórico, indicação, tipos, complicações, protocolo e assistência psicossocial|(5-7). Outras investigações analisam a organização e sistematização da assistência de enfermagem ${ }^{(8,9)}$, os aspectos emocionais das equipes ${ }^{(10)}$ e manuseio da dor ${ }^{(11)}$.

A literatura consultada ${ }^{(12,13)}$, também, evidenciou a importância de compreender e incorporar a experiência dos pais no processo de transplante de medula óssea de seus filhos. Neste sentido, nosso trabalho com crianças/adolescentes, seus pais e familiares em unidade de TMO evidencia algumas dificuldades relacionadas a trajetória de vida desta clientela: mudanças e limitações decorrentes da terapêutica, alteração na dinâmica familiar, interrupção do processo de escolarização, complicações de ordem física e psico-social, longos períodos de internação, reinternações freqüentes, necessidade de isolamento protetor, terapêutica agressiva e a possibilidade de insucesso. Desta forma, o objetivo deste estudo é compreender como os pais e outros familiares de crianças e adolescentes submetidos ao TMO vivenciam esta experiência, especialmente na fase pós-TMO.

\section{METODOLOGIA}

Este é um estudo do tipo descritivo-exploratório e para o alcance do objetivo proposto utilizamos a abordagem qualitativa pois esta tem como fundamento que o conhecimento sobre os indivíduos só é possível a partir da descrição da experiência humana, tal como ela é vivida e definida por seus próprios atores ${ }^{(14)}$.

Para selecionar os participantes, inicialmente solicitamos do Serviço de Arquivo Médico e Estatística (SAME) do Hospital das Clínicas da Faculdade de Medicina de Ribeirão Preto da Universidade de São Paulo a relação de todos os pacientes submetidos ao TMO, assinalando aqueles que possuíam idade inferior a 18 anos, no momento do transplante. Considerando que esta modalidade terapêutica foi ali iniciada em 1992 e que o número de pacientes/ano não era demasiadamente grande, decidimos pela totalidade dos pacientes. De acordo com este critério, obtivemos uma relação de vinte e um pacientes dos quais dez já haviam morrido.

Assim, a partir dos onze pacientes em acompanhamento buscamos seus pais ou responsáveis, ficando a amostra constituída por treze participantes pois em duas situações houve a participação de outro membro da família.

Quanto à procedência, uma adolescente veio encaminhada do estado de Tocantins; uma criança do estado da Bahia, residindo atualmente em Ribeirão Preto e as demais do estado de São Paulo, sendo uma de Ribeirão Preto e seis de diferentes cidades da região. As duas restantes vieram encaminhadas de outras regionais de saúde.

Os responsáveis pela criança ou adolescente nas fases pré, trans e pós transplante foram, em apenas uma situação o marido da adolescente; dois casos tinham a irmã e os oito restantes a mãe; uma das crianças deste grupo, além da mãe tinha também a irmã e um outro o pai.

A idade dos responsáveis variou de 22 a 53 anos, sendo que seis encontravam-se na faixa etária de 22 a 28 anos e sete entre 34 e 53 anos.

O grau de escolaridade dos responsáveis variou, apresentando somente uma mãe analfabeta. Os pais de uma das crianças tinham nível superior e três outros responsáveis tinham segundo grau completo; cinco informaram escolaridade da segunda à quinta série do primeiro grau; um possuía o primeiro colegial e outro o primeiro grau completo.

Quanto ao sexo das crianças e adolescentes, cinco são do sexo masculino e seis do feminino. No momento do transplante, as idades eram variadas, pois o paciente mais novo tinha 3 anos e o mais velho 17 anos. Se os agruparmos por faixa etária, verificamos que seis deles tinham menos de 10 anos, quatro mais de 10 e um possuía 10 anos completos.

Com relação ao diagnóstico que ocasionou o TMO, seis tinham Anemia Aplásica na forma grave, dois Leucemia Mielóide Crônica, dois Leucemia Mielóide Aguda e um Leucemia Linfóide Aguda. Todos os pacientes receberam TMO alogênico.

Todos os doadores eram parentes consangüíneos, sendo seis irmãs, quatro irmãos e um pai. Quanto aos dias transcorridos pós-TMO, encontramos uma grande variação. A criança que apresentou menor tempo tinha realizado o transplante há 190 dias (em torno de seis meses) e a com maior tempo 5 anos e 4 meses, aproximadamente. A maioria dos pacientes (sete) tinha mais de 3 anos de transplante.

Em respeito à Resolução 196/96 do Conselho Nacional de Saúde, que traz as diretrizes para pesquisas que envolvem seres humanos ${ }^{(15)}$, a fase de coleta de dados empíricos do presente estudo foi iniciada após aprovação do protocolo de pesquisa pelo Comitê de Ética em Pesquisa do Hospital das Clínicas da Faculdade de Medicina de Ribeirão Preto da Universidade de São Paulo (Protocolo n 1861/98).

Utilizamos como instrumento para coleta de dados a entrevista semiestruturada com a mãe ou responsáveis pelo cuidado e no início de cada uma apresentávamos e discutíamos o termo de consentimento informado, que teve anuência de todos os participantes. Solicitávamos, também, permissão para que as entrevistas fossem gravadas e não houve recusas. Este procedimento auxiliou-nos na transcrição fidedigna das informações. Os erros gramaticais grosseiros da língua portuguesa encontrados nas falas foram abolidos, porém tomamos cuidado para preservar o sentido delas, de tal forma que o conteúdo não fosse descaracterizado.

As entrevistas foram realizadas por uma das autoras desta pesquisa e tiveram uma duração média de 60 minutos e, preferencialmente, foram realizadas durante os retornos ambulatoriais (4 entrevistas). Naquelas em que não houve coincidência dos retornos realizamos visitas domiciliares ( 6 entrevistas) e em um caso foi realizada durante a reinternação hospitalar.

Para termos uma visão mais global desta fase, registramos em um diário de campo as principais impressões obtidas de cada entrevista, com especial atenção para a comunicação não-verbal: entonação, risos, pausas e hesitações.

A estrutura básica da entrevista constou de duas questões norteadoras: 1. Quais as dificuldades vivenciadas no cuidado diário, no lar, com as crianças/ adolescentes na fase pós-TMO? 2. Quais são as sugestões para a melhoria da qualidade de vida da criança/adolescente e da família na fase pós-TMO?

Na pesquisa qualitativa, como em outras abordagens, o respeito ao anonimato e sigilo são particularmente importantes, pois em pequenos espaços sociais ou grupos reduzidos, em geral, através de alguns descritores é possível identificar os sujeitos. Assim, para minimizar esta associação, cada entrevista está identificada a partir de uma numeração crescente, onde a primeira recebeu a codificação $E_{1}$ e, assim, sucessivamente. Com este procedimento procuramos evitar que as identificações pessoais fossem associadas às informações.

Operacionalizamos a análise dos dados tendo por referência a proposta de organização composta dos seguintes passos: ordenação dos dados, classificação dos dados e análise final(16).

Iniciamos a primeira etapa - ordenação dos dados - com a transcrição das fitas e leitura do material empírico, procurando ordená-lo em agrupamentos; neste primeiro momento, definidos pelo corpo das observações. Este procedimento possibilitou-nos criar diversos títulos em torno dos quais aglutinamos os dados brutos, elaborando, desta forma, uma primeira visão de conjunto. Após esta fase, passamos à classificação dos dados realizando leitura exaustiva e repetida do conjunto do material obtido (leitura flutuante), buscando uma maior 
aproximação dos dados coletados, com o objetivo de identificar as idéias centrais e aspectos relevantes existentes nos conteúdos destes dados. Realizamos este processo com base na revisão da literatura e nos objetivos propostos para o desenvolvimento desta pesquisa.

Dessa forma, esse processo permitiu-nos agrupar os títulos por sua semelhança, constituindo-se em sub-temas e por fim a definição de temas mais abrangentes, como se segue: impacto do transplante e 0 cotidiano familiar.

\section{RESULTADOS E DISCUSSÃO}

\subsection{Impacto do transplante}

A doença, em especial a crônica e grave, apresenta-se como um caminho longo e difícil a ser percorrido pelo doente e sua família e diante da complexidade deste processo é necessário a compreensão de seu impacto.

No transcorrer desta trajetória pudemos identificar fases nas quais as famílias vivenciaram momentos marcantes. Para exemplificar:

Depois que ele fez o transplante assim ... já vai fazer três anos, eu não posso falar qual o momento mais difícil e qual o mais fácil, porque cada época é uma coisa que vai mudando, aí que você vai aprendendo. O que vai sendo mais fácil ou mais difícil ... E mais fácil foi que ele aceitou bem, teve força de vontade; o mais difícil é que ele deixou de ser criança, porque ele não pode fazer o que criança faz, é duro você não poder ... seu filho não poder brincar ... (E.4).

Observamos, através dos depoimentos, que os pais e familiares vivenciam a temporalidade em cada fase do TMO: 0 surgir, o lidar e a perspectiva de futuro.

É, foi o início do tratamento quando nós descobrimos ... foi difícil. Foi um choque. Essa fase foi ... (E.9).

Foi agora. Antes de descobrir o problema dele foi um choque muito grande, e depois desse novo tratamento, sabe a segunda volta, foi pior. Acho que foi, nossa! (E.2). [Esta criança apresentou recaída após a realização do TMO alogênico].

Os familiares e a criança ou adolescente em processo de TMO vivenciam situações e formas diversas para lidar com a complexidade deste procedimento. Cada situação familiar é única e cada família interpreta e responde à doença de uma forma própria. Diante destas questões, deve haver um acompanhamento em todas as fases do TMO para auxiliar as famílias em suas dúvidas, revoltas, indagações e inquietações.

Embora o objetivo deste trabalho seja discutir e analisar a fase pósTMO, o período anterior a ela, em especial a hospitalização, mostrouse significativo para os familiares, e foi freqüentemente rememorado. Através das entrevistas pudemos identificar que o período de hospitalização foi percebido pelos pais e responsáveis como uma fase em que as complicações decorrentes do tratamento, separação dos membros da família, longos períodos de internação, terapêutica agressiva e o isolamento protetor, tornaram-se motivo de preocupação.

Do jeito que eu vi ele, às vezes, eu vi ele internado assim, às vezes eu até chorava de ver ele ali, porque ele ficava muito nervoso, ficava preso num quarto, só num quarto, só deitado. Então, era muito difícil ver ele assim ... (E3).

Durante o processo de hospitalização as crianças e os adolescentes, em geral, tornam-se mais dependentes solicitando, com freqüência, a presença da mãe ou acompanhante:

... Ela não conseguia aceitar eu sair pra fazer alguma compra quando eu tava lá dentro ... (E.1).

Os conceitos de dependência e autonomia são inerentes à natureza humana e quanto mais novo o indivíduo, maior é o grau de dependência, no entanto, com a hospitalização muitas atividades que a criança já desenvolvia de forma independente passam a ser praticadas pela mãe ou enfermagem ${ }^{(17)}$.

A participação dos pais e ou responsáveis no tratamento não termina com o final da hospitalização, pois a continuidade do cuidado no ambiente domiciliar é necessária. Os regimes de tratamento complexos e a contínua monitorização do crescimento e desenvolvimento, levam os pais a desenvolverem habilidades específicas para cuidar de seus filhos, paralelamente às suas responsabilidades familiares. Assim, 0 cuidado à criança com doença grave requer dos pais e demais familiares maior gasto de energia, tempo, recursos financeiros e diminuição da privacidade ${ }^{(18)}$.

Através da entrevista, observamos que cabe aos pais, em especial a quem vai assumir o papel de cuidador, as seguintes atividades rotineiras: preparar a alimentação, manter a higiene da criança e do ambiente, proporcionar conforto e segurança. Além destes cuidados que podem ser considerados básicos, devem aprender a executar procedimentos específicos, ou seja, administrarem medicações que fazem parte da terapêutica, seguirem as orientações para pacientes imunossuprimidos, além de acompanharem em consultas ambulatoriais ou outras internações, quando necessário. Para o cuidador, estas tarefas representavam uma sobrecarga de trabalho:

Tinha muito trabalho, era o dia inteiro, dando aquela lista enorme de remédios, fervendo água, fazendo tudo cozido, limpando o quarto três vezes ao dia, lavando o banheiro duas vezes e roupas de cama eu trocava três vezes, tudo limpinho ... (E.6).

Assim, o cuidado aumentou mais um pouco, né, limpo o quarto dela bem limpinho, o banheiro que ela usa, também é lavar roupa, passar roupa ... (E.1).

Aos cuidados referentes à alimentação, além do seu preparo, somamse outros encargos como cuidados com a limpeza e cozimento dos alimentos, responsabilidade de fornecer o suporte calórico e a ingestão de líquidos.

Diante da alteração do hábito alimentar, decorrente do tratamento, a criança ou o adolescente pode apresentar náuseas e vômitos, anorexia, restrições a alguns alimentos, exigências de cardápio variado e resistência em aceitar determinado tipo de alimento.

Ela não comia normal, até fruta tinha que ser ou cozida ou assada, ela não comia de jeito nenhum. Ela enjoou de carne, ela não comia mais carne. Ela pegou assim nojo de carne, principalmente de frango. Depois que ela voltou a comer o que mais teve problema foi de ser tudo cozido. Água tinha que ser fervida. Até hoje, agora a gente faz ... ela bebe mais mineral agora. Ela passava muito mal do estômago ... Foi o problema que ela teve mais grave ... (E.5).

A limpeza da casa, considerada um cuidado trabalhoso e de desempenho diário, como depende mais de quem a executa do que da vontade do doente, era realizada de uma forma mais tranqüila. Manter o ambiente limpo e arejado, as roupas e os utensílios domésticos limpos e organizados faziam parte desta rotina... Super limpo, tudo. A gente limpava tudo, lavava ... (E.10).

Observamos que os cuidados destinados à medicação referiam-se à sua administração, seguindo rigorosamente a prescrição e orientação médica, com seus horários, dosagens e medicamentos corretos. Como este cuidado não estava inserido no cotidiano familiar, antes da existência da doença, trouxe consigo sentimentos de insegurança e medo de cometer algum erro. À medida que o tempo passou, esta dificuldade diminuiu, como pode ser visto neste depoimento:

As medicações (...) é eu que dou tudo certinho, graças a Deus tô acertando. No início foi meio difícil mais principalmente naquele dia na saída do TMO, foi muito difícil pra mim encaixar na minha cabeça e eu achei que era coisa de sete cabeças mesmo, difícil!! ... a sorte que foi rapidinho. Eu consegui dar conta de toda medicação certa 
pra ela. Foi tudo, não foi tão difícil de mais se for ver agora. Mais no começo foi difícil, caramba! (E.1).

Pelas falas dos entrevistados verificamos que os cuidados vinham acompanhados de muito rigor na sua execução e seguiam as orientações da equipe do TMO.

... Tudo, tudo. A gente fez a risca. Tudo que o médico mandava, a gente fazia ... A gente nunca fez nada que fosse sem falar com 0 médico, nada, nada ... (E.5).

... Fizemos a risca mesmo já que é pra fazer tem que fazer direito. A gente não queria que nada desse errado, então, fizemos tudo, tudo, tudo ... (E.10).

Observamos que a rotina diária da criança/adolescente e seus familiares em relação aos cuidados envolvia retornos constantes ao hospital, encargos financeiros, cuidados rigorosos que aumentavam as suas responsabilidades, além de terem que atender às necessidades dos outros membros da família, tornando-se um grande desafio para as mesmas.

O cuidado ao paciente se dá na perspectiva de estar junto, no planejamento de ações, na orientação e no estabelecimento de vínculo com a criança, adolescente e família, portanto consideramos que 0 suporte profissional, em particular o de enfermagem, está vinculado aos cuidados básicos de enfermagem (cuidados higiênicos, alimentares, terapêuticos, conforto), ao envolvimento emocional e às ações educativas, com intuito de auxiliá-los no processo saúde-doençacuidado.

\subsection{0 cotidiano familiar}

Quando uma criança ou adolescente adquire uma doença grave e necessita de um tratamento complexo, toda a estrutura familiar, em seu âmbito físico, psicológico e social, fica afetada. Ocorrem mudanças na sua estrutura que variam de acordo com os níveis de gravidade, dependendo da doença da criança, do quadro clínico e do suporte dos demais membros da família.

As limitações impostas pelo tratamento envolvem tanto a família quanto a criança ou adolescente e estão relacionadas ao trabalho, atividades sociais e escolares.

Eu parei de trabalhar para vir cuidar dele, também tive que largar a escola porque eu estava estudando, eu tive que sair, daí parei de estudar. Quando ele foi embora eu ainda fiquei um tempo em casa ... (E. 3).

É tudo diferente, muda tudo ... (E.5).

Com o decorrer do tratamento, o responsável pelo cuidado defrontase com a necessidade de coordenar estas novas atividades com os cuidados e tarefas do cotidiano familiar. Ao mesmo tempo em que deveria estar junto do paciente, cuidando, vigiando e protegendo, deveria manter suas atividades rotineiras, levando a uma reestruturação da vida familiar.

Na fase pós-TMO, os pais, outros familiares e a criança/adolescente necessitam alterar uma série de atividades para seguirem o protocolo terapêutico. Assim, seu modo de vida e comportamento sofrem ajustamentos.

Ao se submeter ao TMO, a criança/adolescente passa a viver com restrições e viver, desta forma, é ter que adequar a vida a certos limites estabelecidos em função da prioridade de cada um. Se antes a prioridade era viver, crescer e ter liberdade, agora é zelar, proteger, tratar, ou seja, cuidar para não morrer.

No contexto de tratamento a criança ou adolescente, em função de sua nova prioridade, terão de se submeter à mudanças em suas vidas, partindo para as restrições de atividades, de relações, de hábitos e até de perda de liberdade. Terão que incorporar nas atividades do dia-a-dia cuidados e costumes que até então não existiam. Haverá um distanciamento dos seus amigos devido à própria condição física e limitações decorrentes do tratamento. Isso acarreta um forte elo com sua cuidadora e até mesmo um amadurecimento diante da responsabilidade dos cuidados necessários.

Depois que ele fez o transplante ficou adulto, eu não sei se é a responsabilidade de ficar assim, fazendo essas coisas de limpeza, de ficar lavando a mão, de responsabilidade de tomar os remédios, de tomar aquele tanto de quantidade de líquidos. Ele tem responsabilidade. Hoje ele só tem amizade com adulto, só com adulto, ele não tem amizade com nenhuma criança. Eu acho que ele não tem amizade com criança porque ele não pode brincar. Do jeito que ele fala, o brincar; criança sobe na árvore, pula muro, joga bola no sol quente, vai nadar no corguinho, vai fazer isso ... vai fazer aquilo ... Ele não consegue acompanhar essas crianças. Então, ele tem amizade com adulto (E. 4).

A força de vontade, colaboração e responsabilidade da criança/ adolescente auxilia e encoraja a família para prosseguir a jornada.

... Ele tem responsabilidade, sabe, você pode confiar nele; ele não come certas coisas, não bebe assim as coisa na rua, assim sorvete em qualquer lugar, se ele for num lugar que está sujo ele tem responsabilidade ... eu acho que eu e o J. vamos conseguir sim, o J. tem muita força de vontade de ficar bom ... (E. 4).

As famílias sentem-se revoltadas com as perdas que as crianças e adolescentes sofrem durante 0 tratamento. Para elas, vê-los diferentes dos demais é uma experiência difícil.

... Pra mim foi difícil ver ele diferente. Tem hora que eu fico revoltada, porque eu queria que ele fosse criança ... Tinha tempo de ser moço ... (E. 4).

Pudemos identificar, nas entrevistas, que a vida, antes normal, passa a ser regulada por horários, remédios e tratamentos. Assim, em decorrência da terapêutica surgiram alterações da auto-imagem que afetaram a vida da criança/adolescente.

... Sair na rua com aquela máscara as pessoas ficavam perguntando por que ela usava aquilo. Às vezes, ficava olhando assim, como se ela tivesse uma doença que ia contaminar os outros ... (E. 6).

... O cabelo caiu e ela ficou deprimida ... os pelos, ela ficou muito peluda (E. 6).

De modo geral, a adolescência caracteriza-se por alterações físicas decorrentes do crescimento e desenvolvimento normal, gerando mudanças na sua auto-imagem. Muitos adolescentes enfrentam dificuldades ao se depararem, por exemplo, com o crescimento dos pelos, a mudança na voz, o desenvolvimento dos órgãos genitais. Estas dificuldades tendem a se acentuar nos adolescentes com câncer, uma vez que os efeitos colaterais dos quimioterápicos, como a queda de cabelos e a neutropenia, que exige o uso de lenços, bonés, chapéus e máscara, tornando-os diferentes das outras pessoas, gerando sentimentos de angústia, que podem levá-los ao isolamento social ${ }^{(19)}$. Outros estudos ${ }^{(20,21)}$ também mostraram estas dificuldades enfrentadas pelas crianças e adolescentes com câncer.

As famílias procuraram manter um estilo de vida muito próximo do que viviam antes da experiência da doença, tentando levar uma "vida normal", com intuito de conviverem com a situação e se adaptarem a ela. Os dados obtidos mediante as entrevistas mostram-nos que mesmo com a realização de um tratamento longo, que inspira cuidados especiais e impõe tantas limitações, a vida era considerada, muitas vezes, normal para as famílias, porém o "padrão de normalidade" variava de família para família, pois umas consideravam a vida mais normal que outras.

Depois do transplante cuidados a gente tem direto, ela voltou à vida quase normal. Agora ela pode sair, mas a gente tá sempre com aquele cuidado. (E. 5).

Não tem como ser normal, só se for daqui mais um tempo, mas até 
agora nos três anos, não é não, por mais que pareça normal e tudo, mas tem uma preocupação diferente que a gente tem com ela ... (E. 8).

Nesta perspectiva, a doença passa a fazer parte do cotidiano das famílias onde era vivenciada dia-a-dia. Viver um dia de cada vez significa lidar com a doença a cada dia, ou seja, na medida que surgiam novas situações, que poderiam se prolongar por diversos anos, elas as enfrentavam.

Cada época tem uma fase para você passar ... (E.4).

Os momentos permeados pelo medo, incerteza e insegurança traziam a dúvida com relação ao sucesso do tratamento, o receio de surgirem as complicações e a dualidade entre a vida e a morte. Nesta perspectiva a família vivenciava o contexto de incerteza.

A possibilidade de transplante surgiu como uma alternativa para a situação diária de viver com uma doença crônica potencialmente fatal, mas quando ele ocorreu, trouxe esperanças de um futuro permeado por incertezas, as quais estavam relacionadas ao fato de terem que encarar um procedimento relativamente novo, o TMO, e juntamente veio o medo do desconhecido. Os pais e/ou responsáveis ficavam assustadas com o prognóstico e com a quantidade de decisões a serem tomadas.

As descrições feitas por eles, ao viverem estas ameaças, refletem, até certo ponto, o estado de saúde das crianças/adolescentes.

O momento mais difícil que eu fiquei só comigo foi de dar alguma rejeição, porque sempre quando fala de transplante, corre o risco de ter uma rejeição, aí eu fiquei assim só comigo assim bem triste um pouco (E. 1).

Era o medo de pegar infecção (E. 4).

Medo de ter perdido ela ... O que marcou Nossa Senhora. Até hoje, eu converso com o meu marido, ele chora, ele chora de pensar nisso, de ter perdido ela. Deus me livre (E. 5).

As famílias de pacientes submetidos ao TMO, vivem em constante estado de incerteza pelos riscos, em potencial, de infecções, hospitalização prolongada, procedimentos médicos invasivos e a possibilidade da morte ${ }^{(12)}$.

Para enfrentarem a doença e seu tratamento, elas recorrem à espiritualidade, fé e crenças buscando forças para cuidarem da criança/ adolescente e para não se sentirem sozinhas na luta pela vida. Nesta busca, encontraram o apoio necessário:

... Mas só que a gente confia muito em Deus. Entrego nas mãos de Deus mesmo, pego, falo a gente tem muita fé em Deus. Deus vai curar ele com certeza e aí a gente entrega nas mãos de Deus, a luta foi muita, foi muita luta mesmo, não foi fácil prá gente ... (E. 11).

Com tanta fé e esperança que eu tinha ... que tinha certeza que no final ia dar certo. $E$ deu! (E. 6).

\section{CONSIDERAÇÕES FINAIS}

A existência de uma doença grave ocasiona profundas transformações nas vidas da criança ou do adolescente, portadores dela e na sua família gerando, assim, momentos que desencadeiam expectativas de diferentes naturezas. Desta forma, a família reestrutura o seu cotidiano para re-aprender a cuidar da criança/adolescente. Com isto, um novo cotidiano configura-se buscando a adaptação à nova rotina, onde o cuidado diferenciado passa a fazer parte da tarefa diária da família. Este cuidado traz novas responsabilidades, encargos e dificuldades para crianças/adolescentes e seu familiares.

No transcorrer deste processo, a hospitalização permanece presente na vivência das famílias com repercussões ainda na fase pós-TMO, fato que nos revela a importância que este período tem para as famílias se considerarmos que a hospitalização é a concretização do TMO, pois com seu início propriamente dito, ela começa sua jornada para o sucesso do tratamento.

A partir desta etapa, recai sobre a família do doente grande parte do cuidado básico e especializado que the deve ser dispensado, o qual está centrado, na maioria das vezes, em apenas um cuidador familiar, geralmente a mãe. Assim, o paciente recebe um alto nível de proteção, que contribui para estabelecer uma relação de dependência, muitas vezes exacerbada, levando o paciente a manter-se "estéril até da própria vida". Por isto, devemos estimular desde a hospitalização, o auto-cuidado da criança e do adolescente, na medida do possível, mantendo a sua independência, confiança e auto-estima, para que a responsabilidade do cuidado não recaia somente sobre o cuidador. Este processo requer 0 apoio de toda a família e a contribuição dos profissionais de saúde.

Consideramos fundamental que a equipe de saúde repense a própria forma de organizar o cuidado prestado a estes pacientes, buscando caminhos que possam atenuar as dificuldades vivenciadas pelos familiares, seja com a ampliação do acompanhamento, ambulatorial ou domiciliar, com a formação de grupos e casas de apoio.

Diante da complexidade do TMO, é indispensável conhecermos a realidade familiar do paciente pois esta tem papel fundamental na sua qualidade de vida. Identificar as condições, vivências e modo de vida das famílias, permite-nos trabalhar com base na realidade de cada uma, respeitando suas possibilidades e seus limites.

\section{REFERÊNCIAS}

1. Wiley F, House K. Bone marrow transplant in children. Semin Oncol Nurs 1988; 4(1): 31-40.

2. Sanders JE; Buckner CD; Sullivan KM; Doney K; Applebaun F Witherspoon $\mathrm{R}$, et al. The impact of marrow transplant preparative regimens on subsequent growth and development. Sem Hem 1991; 28: $244-9$.

3. Treleaven J. Late effects of bone marrow transplantation. In: Treleaven J, Wiernik P. Color atlas and text of bone marrow transplantation. London (UK): Mosby - Wolfe; 1995. p. 193-9.

4. Pasquini R, Ferreira E. Transplante de medula óssea. In: Oliveira MP. Hematologia clínica. $3^{\mathrm{a}}$ ed. Rio de Janeiro (RJ): Atheneu; 1990. p. 561-77.

5. Silva MR. Enfermagem em transplante de medula óssea. Rev Enferm Complexo Hosp Clínicas da FMUSP 1997; 1(1): 27-30.

6. Abramovitz LZ, Senner AM. Pediatric bone marrow transplantation updadte. Oncol Nurs Forum 1995; 22(1):107-15.

7. Ishida $\mathrm{ACH}$, Sainatto SM. Assistência de enfermagem no transplante de medula óssea. In: Cursino MR. Assistência de enfermagem em

pediatria. São Paulo (SP): Sarvier; 1992. p. 167-170.

8. Clark JC, McGil RF. Enfermagem oncológica: um currículo básico. $2^{\mathrm{a}}$ ed. Porto Alegre (RS): Artes Médicas; 1997.

9. Ahana $D$, Kunishi M. Protocolos de enfermagem para tratamento do paciente oncológico. $2^{\mathrm{a}}$ ed. São Paulo (SP): Andrei; 1992.

10. Molassiots A, Habernan M. Evaluation of burnont and job satisfaction in marrow transplant nurses. Cancer Nurs 1996; 19(5): p. 360-7.

11. Pederson C, Parran L. Bone marrow transplant nurses, knowledge, beliefs and attitudes regarding pain management. Oncol Nurs Forum 1997; 24(9): 1563-71.

12. Foxall MJ, Gaston-Johansson F. Burden and health outcomes of family caregivers of hospitalized bone marrow transplant patients. J Adv Nurs 1996; 24: 915-23.

13. Compton $\mathrm{K}$ et al. Understading the caring relationship during marrow transplatation: family caregivers and healthcare professionals. Oncol Nurs Forum 1996; 23(9): 1428-31.

14. Polit DF; Hungler BP. Fundamentos de pesquisa em enfermagem. Tradução de Regina Machado Garcez. $3^{a}$ ed. Porto Alegre (RS): Artes 
Médicas; 1995.

15. Ministério da Saúde. Conselho Nacional de Saúde. Diretrizes e normas reguladoras de pesquisa envolvendo seres humanos. Brasília (DF): Ministério da Saúde; 1997.

16. Minayo MCS. O desafio do conhecimento: pesquisa qualitativa em saúde. São Paulo (SP): Hucitec; 1992.

17. Lima RAG. Criança hospitalizada: a construção da assistência integral [tese]. Ribeirão Preto (SP): Escola de Enfermagem de Ribeirão Preto; Universidade de São Paulo; 1996.
18. Sterling YM. Parent's resources and home management of the care of chronically ill infants. JSPN 1996; 1(3):103-9.

19. Menossi MJ, Lima RAG. A problemática do sofrimento: pecepção do adolescente com câncer. Rev Esc Enferm USP 2000; 34(1): 45-51.

20. Bonassa EMA. A enfermagem em quimioterapia. São Paulo (SP): Atheneu; 1992.

21. Vendrúsculo J. A criança curada de câncer: modos de existir [dissertação]. Ribeirão Preto (SP): Faculdade de Filosofia, Ciências e Letras de Ribeirão Preto; Universidade de São Paulo; 1998. 